\section{Public Health Genomics}

Public Health Genomics 2010;13:389-395

DOI: $\underline{10.1159 / 000294582}$
Received: September 16, 2008

Accepted after revision: March 2, 2010 Published online: July 9, 2010

\title{
Recruiting American Indian Women for a Genetic Epidemiology Study
}

\author{
M. Nadeau L. Best \\ Turtle Mountain Community College, Belcourt, N. Dak., USA
}

\author{
Key Words \\ American Indian • Epidemiology • Genetics • Pre-eclampsia • \\ Recruitment
}

\begin{abstract}
Due to previous negative experiences, some American Indian communities are distrustful of research in general and genetic research in particular. The Turtle Mountain Community College was awarded a National Institutes of Health $(\mathrm{NIH})$ grant with 3 aims: (1) to study possible genetic influences on pre-eclampsia, (2) to encourage tribal college students to consider biomedical careers and (3) to develop the local research infrastructure. Retrospectively identified case (91) and control (188) participants were recruited into Phase I over a 3-year period and additional participants (71) were concurrently recruited from a prenatal clinic into a prospective case/control study, Phase II. This paper describes some of the challenges and solutions we encountered in the process of recruiting American Indian participants into a genetic epidemiologic study.

Copyright $\odot 2010$ S. Karger AG, Basel
\end{abstract}

\section{Introduction}

There are many reasons why American Indians (AIs) choose to participate in research. Some participate because they are personally afflicted with the disease that is being studied, or know someone who is, and can person- ally identify with the research. Others participate to improve the health of their community. Many AI tribes have had positive research experiences. One example is the ongoing Strong Heart Study, which began in 1988 to investigate the epidemiology of cardiovascular disease among 13 tribes in different regions of the United States $[1,2]$. The Strong Heart Study has been approved by the participating tribes and individuals during each of 5 separate phases, collected invaluable clinical and genetic information on over 8,000 participants and experienced retention rates in excess of $90 \%$ for each phase.

Community members described in this report have participated in a variety of studies including psychological, sociological, clinical, and genetic research. The first genetic epidemiologic study of this population, the Turtle Mountain Band of Chippewa Indians, was a pilot study conducted by Dr. Lyle Best in collaboration with the University of Pittsburgh which investigated a gene coding for a circulating immune factor and its association with otitis media. The present Genetics and Pre-eclampsia Study is only the second genetic epidemiologic study conducted among this population. Pre-eclampsia (PE) is a late complication of pregnancy recognized by an elevation in blood pressure, leakage of protein into the urine and swelling of the hands and feet. The severity of PE can vary from mild to serious cases which threaten both the mother's and, more commonly, the infant's life. Currently in the United States and worldwide, hypertensive disorders complicate up to $8 \%$ of all gestations [3].

\section{KARGER}

() 2010 S. Karger AG, Basel

Fax +4161306 1234

E-Mail karger@karger.ch

www.karger.com
Accessible online at: www.karger.com/phg
Dr. Lyle Best

Turtle Mountain Community College

PO Box 340

Belcourt, ND 58367 (USA)

Tel. +1 701477 7961, Fax +1 701477 7807, E-Mail sbest@ utma.com 
This investigation was initiated because increased understanding of the genetic influences on PE could be useful to the AI population in the following ways: (1) determining the prevalence of genetic polymorphisms of medical interest in the community, (2) examining the association of these genetic variants with increased risk of $\mathrm{PE}$, and (3) providing important new information on the possible utility of genetic screening for PE in AI populations. The first single nucleotide polymorphisms (SNPs) examined in this study are focused on validating observations from Caucasian populations. Additional, less well characterized SNPs are currently under investigation. None of the selected SNPs are thought to be unique to the AI population. The benefits to the individual participant are minimal, and the consent process emphasizes that this research is primarily intended to help future generations.

In some instances, AI communities may have had expectations of dramatic and rapid advances in the understanding and treatment of disease conditions and the short-term benefits that would accrue from research. This can lead to apathy or resistance to further participation when the anticipated progress fails to materialize. For example, the National Institutes of Health (NIH) has funded the study of diabetes among the Pima Indians since the mid 1980s. In spite of many significant findings and some efforts at translating these results into interventions, the underlying cause of diabetes remains unknown and the condition continues to exact a heavy toll on the population [4]. The perceived lack of progress among this community and others may impede continued research participation.

Of more concern, previous serious breaches of trust and other negative experiences have led some AI people to become distrustful of research in general and genetic research in particular. In regard to genetic studies, much of the distrust stems from population genetic research that has focused on human migration [5], rather than health issues. Tribal nations are rarely interested in research on migration patterns of ancient peoples [6] and may feel their traditions and sacred legends are threatened. Many tribes may feel that there has been insufficient effort by scientists to understand and learn how their communities perceive genetic research [6].

One such negative experience involved the Nuu-chahnulth (Nootka) tribe of British Columbia. Investigators collected samples there with tribal approval to study a particular form of arthritis which afflicted many. Almost 20 years later, in 2002, it was discovered that the samples had also been released for research on population studies completely unrelated to this medical condition. The community was very angry that their data and permission had apparently been misused [7].

A more recent example involves the Havasupai, located south of the Grand Canyon in Arizona. Arizona State University scientists hoped to discover rare gene variants underlying diabetes, and, with the tribe's approval, research was begun in the early 1990s. Subsequent work appears to have gone beyond the approved tribal consent and used unethical practices, resulting in a lawsuit claiming USD 75 million in damages. Tribal members maintain that their civil rights have been violated. The accused researchers blame the dispute on a number of misunderstandings and strenuously deny any wrongdoing [8].

The purpose of this article is to explain the recruitment process for the Genetics and Pre-eclampsia Study, to describe some of the challenges, to share some of the practices we implemented aimed at recruitment and retention, and to offer a variety of recommendations for researchers who are interested in doing systematic investigation with tribal nations. This is not a formal trial of any specific recruiting method or direct comparison of methods. Rather, it is a compilation of findings and impressions gleaned from our experience and recommendations based on our work.

\section{Methods}

\section{Background}

In 2004 the Turtle Mountain Community College (TMCC) was awarded NIH funding through a subcontract with the University of North Dakota IDeA Network of Biomedical Research Excellence (INBRE) program to (1) study possible genetic influences on PE in an AI population, (2) encourage TMCC students to consider a biomedical career, and (3) develop the local research infrastructure so genetic/epidemiologic research can be conducted by AI investigators and the TMCC.

TMCC is one of 6 tribal colleges that were originally established in the early 70s. The Turtle Mountain Band of Chippewa Indians chartered TMCC in 1972. Currently the college serves approximately 468 full-time students and 168 part-time students. TMCC is located in north central North Dakota and offers a variety of certificates, associate and four-year degrees [9]. The college had no prior experience with biomedical research involving human participants and did not have a Federal Wide Assurance or an independent Institutional Review Board (IRB).

The Turtle Mountain Reservation covers a land area of $6 \times 12$ miles and had a population of 6,481 in 2000 (does not include population on Off-Reservation Trust Land). According to the 2000 Census, 96.1\% identified as American Indian and Alaska Native, 3.1\% identified as White, $0.1 \%$ identified as Black or African American, $0.2 \%$ identified as some other race, and 0.5\% identified as 2 or more races. In 1999 the poverty rate was 38\% among 
AIs on the Turtle Mountain Indian Reservation and Off-Reservation Trust Land, and unemployment stood at $70 \%$. The median household income in 1999 was USD 23,269 and the mean travel time to work was $14 \mathrm{~min}$ for workers over 16 years of age [10].

\section{Study Design and Approvals}

The study consists of 2 phases, conducted simultaneously. Phase I identified and recruited cases and controls retrospectively from December 2004 to November 2007. Phase II began concurrent recruiting of prenatal patients in a prospective case-control study during this same period. TMCC registered in the Federal Wide Assurance system for the first time, and arrangements were made to delegate IRB approval authority for this study to the University of North Dakota IRB (IRB of record) and also to the Aberdeen Area IRB. Additional approvals were obtained from the Turtle Mountain Band of Chippewa Indians and the Quentin Burdick Health Care facility, the local Indian Health Service (IHS), administration.

\section{Preparing the Recruiter}

Since the study is being conducted at the TMCC, preference was given to hiring a full-time AI research technician (author Nadeau), who served as the primary recruiter with the Principal Investigator (author Best), overseeing the study. The student research assistants, who worked up to $10 \mathrm{~h} /$ week for the project, were also encouraged to complete the necessary training so they could recruit participants as well. The purpose of training and experience was partially to meet regulatory requirements, but also to teach and familiarize the recruiter and students with the following: the skills necessary to conduct a genetic research project, important laboratory methods for genetic research, biomedical research facilities, protection of human research subjects and vulnerable populations, networking and developing collaborations, current research being conducted with tribal nations, presentation skills, role-modeling for their fellow community college students, and the world of research in general. The recruiter and students (time permitting) completed a number of training sessions, such as: (a) confidentiality, Health Insurance Portability and Accountability Act (HIPAA), Privacy Act training; (b) the process of obtaining informed consent; (c) risks and benefits of genetic research for participants; (d) lab safety, Occupational Safety and Health Administration universal precautions; (e) the scientific method and basic research design; (f) basic polymerase chain reaction, electrophoresis techniques; (g) data entry software, computer security; (h) basic forms of statistical analysis; (i) literature search, library/internet methods; (j) scientific writing, presentations.

The recruiter and students were also encouraged to visit a number of labs and attend various annual meetings. The principal investigator (author Best) believes it is important to train and recruit AIs for the study because AIs and other minority groups are under-represented in medical careers and among biomedical researchers. It is hoped that training and experience will generate student interest in further studies that lead to a medical or a biomedical research career.

\section{Recruiting for Phase I - Cases and Controls}

For Phase I of the study, we used a case-control retrospective design. The IHS electronic records system, the Resource and Patient Management System (RPMS), was queried for the period from June 1990 (when RPMS began) through December 2004, to identify patients diagnosed with PE (potential cases). Most potential cases, approximately $80 \%$, were identified by means of this electronic record system, using ICD9 codes (642.40-642.74) which were designed to be inclusive.

The RPMS system was also queried periodically from December 2004 to November 2007 to ascertain new potential cases that may or may not have been recruited through the Phase II process. A detailed description of the diagnostic criteria for PE cases has been published [11]. Additional potential cases, approximately $20 \%$ of the total, self-identified as having PE after finding out about the study. We later confirmed those who had self-identified after gaining their consent to participate through chart review to identify whether they had at least 2 of the following after 20 weeks of gestation: (1) blood pressure values above either 140 systolic or 90 diastolic; (2) proteinuria as indicated by at least two +1 dipstick measurements; (3) a diagnosis of 'pre-eclampsia' or 'eclampsia' by an attending physician. These criteria were chosen to be compatible with the National Hearth, Lung, and Blood Institute Working Group on Research on Hypertension during Pregnancy definition but to also consider the clinical judgment of the attending physician [3]. Patients were only excluded if they were under the age of 16 at the time of recruitment.

Controls were selected by identifying women who delivered the first infant before and the first infant after the case. If this individual could not be recruited, then the next closest delivery would be selected. This method of selecting controls was chosen as a means to control for possible seasonal influences on PE [12].

Once identified, potential participants were contacted, primarily by phone, to see if they were interested in hearing more about the study. Every effort was made to recruit the first individual contacted, even if she no longer lived in the area, in an attempt to avoid selection bias due to possible difference between individuals that no longer lived in the area compared to those who did. Recruiters arranged to meet in person with potential participants in their homes or another convenient location in order to complete the process of informed consent and mileage was recorded and used in the analysis. Participants were asked if they would like to read the consent form or if they preferred to have it read to them. Once the process of informed consent was complete, potential participants provided a capillary blood sample for DNA extraction and later analysis of SNPs potentially influencing the risk of PE. If a potential participant decided to join the project, they were given a choice between 2 gifts: a beaded lanyard or a USD 10 gift certificate.

\section{Recruiting for Phase II - Prospective/Prenatal Case-Control}

All women over the age of 15 years and less than 20 weeks gestation, attending a prenatal clinic at the local IHS, were eligible to participate. We did not receive a list of eligible participants from IHS, so the recruiter was responsible for identifying potential participants. At the local IHS, patients can call and schedule a prenatal appointment for Monday-Friday, 8:00 AM-4:30 PM. There is also a $4 \mathrm{~h}$ prenatal clinic on Wednesdays from 8:00 AM to noon every week where patients are free to walk in without a scheduled appointment. Due to time constraints with the project and the fact that potential prenatal participants could be more easily identified by the recruiter during walk in clinic, recruitment efforts focused on the walk-in clinic. A recruiter was present each week during the walk-in prenatal clinic from 9:00 AM until noon. 
Eligibility criteria for Phase II of the study included being at least 16 years of age, being pregnant at the time of recruitment and receiving prenatal care at the local IHS. Once recruited, a systematic review of written medical records was conducted a few months after delivery to identify subjects who had signs and symptoms of PE. Phase II participants not identified with PE served as controls when possible. If a Phase II participant that delivered within one month of an identified case was not available to serve as a control, a non-Phase II control was identified using RPMS. As in Phase I of the study, controls were selected by identifying women who delivered the first infant before and the first infant after the case. Again, every effort was made to recruit the first individual contacted, even if she no longer lived in the area. If this individual could not be recruited, then the next closest delivery would be selected.

The following recruiting method seemed to be the most effective. After introducing herself and the project, the recruiter would ask a woman in the prenatal clinic waiting area if she might be pregnant; if so, the recruiter would give her a brief introduction about the project and provide her with an invitation letter, introductory pamphlet, newsletter, consent form, HIPAA form, and recruiter contact information. Once the potential participant reviewed the information, the recruiter would then answer any questions she might have, and, if interested, she would consent to join the study.

Other recruiting tactics were tried to reach the prospective/ prenatal cohort, but were limited in their effectiveness. The local IHS providers were asked to identify potential prenatal participants and introduce them to the study staff. Letters containing recruiter contact information were sent out, informing patients about the project. Contact information cards were also available for providers to give patients who did not have time to meet with the recruiter. This allowed the patient to fill in her contact information on the card and return it in a prepaid self-addressed stamped envelope.

We also tried a number of advertising efforts. From the beginning of the study, a 2' $\times 3$ ' poster describing the project and contact information was displayed at the local IHS clinic. Flyers that describe the project were hung throughout the community in various locations, including local grocery stores, the IHS hospital/ clinic and the local mall. Interviews about the project were featured on the local radio station. Pamphlets were distributed at local health fairs and in other communities. A video (shown at the local IHS prenatal clinic) was developed by tribal college research assistants to describe the project and introduce the personnel involved. Finally, quarterly meetings were held with an elders group of the Turtle Mountain Band of Chippewa.

\section{Results}

\section{Challenges Recruiting for Phase I-Cases and \\ Controls}

Contact information in the RPMS system frequently contained disconnected or inaccurate telephone numbers. One reason for this may be that this is a very mobile community. Many community members move to attend school, to live in the urban community with other family members and to seek employment. Another reason for disconnected or inaccurate numbers could be the result of the high unemployment rate or simply because an individual may temporarily need the 'phone bill money' for an unexpected expense [13]. If a valid, current number was available, it was difficult to determine a good time to call. If there was no valid number, the recruiter would attempt to contact the potential participant through any listed emergency or next-of-kin contact information, using RPMS. Even though contact information for these individuals also contained disconnected or inaccurate telephone numbers, when accurate information was listed, the recruiter was able to successfully get in touch with a number of potential participants. Since many of them were initially confused about how the study obtained their contact information, the recruiter explained this early in the introduction.

If a potential participant requested a home visit, it could be difficult locating the residence, since most individuals, living on the reservation, do not have a physical address. There are many landmarks that have been named by the community and are familiar to those who live within the community. These landmarks cannot be geographically identified, so having a local recruiter has been very helpful. A number of participants also expressed their appreciation for having a local recruiter versus someone from outside the community. When the recruiter had a last name that is considered a common name in the community, many of the participants knew someone in the recruiter's family. Participants often established rapport with the recruiter by enquiring about the recruiter's family. These impressions are based on informal feedback from participants. Due to time constraints and cost associated with traveling, recruiting those living on and off the reservation was a serious barrier.

\section{Challenges Recruiting for Phase II - Prospective Case-Control Study}

The local IHS is severely understaffed, making provider 'time' an issue. Because of this, it is not feasible to depend on the medical providers to mention the study to a potential participant. Since patients sometimes wait hours for their appointment, they are often unwilling to spend the additional time required for the study. It has also been difficult finding an effective advertising method. The recruiter consistently asked potential participants if they had previously heard about the study. Unfortunately the majority had not, leading the recruiter to conclude that the advertising methods were limited in their effectiveness. Another impediment is the awkward 
nature of enquiring whether a woman might be pregnant and therefore eligible for the study.

\section{Recruitment Rates and Processes for Phase I and Phase II}

From December 2004 to November 2007, 654 individuals were identified ( 575 for Phase I and 79 for Phase II) (table 1). During Phase I, 106 individuals were identified as potential cases. When selecting controls, we had to identify a median number of 2.5 women. Of the 575 women identified in Phase I, 453 (78.8\%) had adequate contact information. These 453 participants were given basic information over the phone and of these 282 (62.3\%) had full consent interviews. For a variety of reasons (often in spite of multiple appointments), we were unable to successfully arrange a full consent interview for the remaining 171 (37.7\%). Of the 361 Phase I and Phase II participants who received full consent interviews, $3(0.8 \%)$ opted not to participate. A full consent interview was more likely to be obtained from potential case participants given introductory consent information (92 from among 126 potential cases), compared with 190 full interviews from a total of 327 identified controls $\left(\chi^{2}=7.98, \mathrm{p}<\right.$ 0.005). A total of 358 participants, 279 Phase I (91 cases and 188 controls) and 79 Phase II ( 2 cases and 6 controls were identified from this group) were recruited. On average 6.2 Phase I participants and 1.76 Phase II participants were recruited per month. The mean age for Phase I participants at the time they joined the study was 32.1 years with a standard deviation of 8.22.

The consent process varied depending on the potential participant. Some potential participants clearly understood what was being asked of them. Others had many questions and needed extra clarification. The process took approximately an hour on average to complete. Most (89.9\%) of the participants (Phase I and Phase II) preferred a USD 10 gift certificate over a beaded lanyard. Local and long-distance travel was required to recruit $82.4 \%$ of Phase I and Phase II participants. Participants living within 4-50 miles round trip of the study office comprised $88 \%$ of the participants, whereas recruitment of the remaining $12 \%$ required round-trip travel of between 50 and 993 miles.

\section{Discussion}

For many years research has been conducted among AI tribes. It is not unusual to hear an AI say, 'We have been researched to death'. Researchers must acknowledge
Table 1. Recruitment numbers at various stages in the process

\begin{tabular}{lccc}
\hline & Phase I & Phase II & Total \\
\hline $\begin{array}{l}\text { Number of potential participants } \\
\text { identified }\end{array}$ & 575 & 79 & 654 \\
\hline $\begin{array}{l}\text { Had adequate contact information } \\
\text { and given basic information }\end{array}$ & 453 & N/A & 453 \\
\hline $\begin{array}{l}\text { Decided not to meet for a full } \\
\text { consent interview }\end{array}$ & 171 & N/A & 171 \\
\hline \begin{tabular}{l} 
Full consent interview \\
\hline Opted not to participate
\end{tabular} & 282 & 79 & 361 \\
\hline Recruited & 279 & 79 & 358 \\
\hline
\end{tabular}

this present day attitude that AI people have about research and should also work to know and understand the impact of historical relations between the US Government and AIs [14]. Despite the fact that tribal nations are heavily studied communities, there are many reasons why individuals choose not to participate in research, including the perception that it (1) takes too much time, (2) makes the person uncomfortable, (3) infringes on privacy, (4) conflicts with religious beliefs, or that (5) making the decision to participate, based on the pros and cons of the research, is too complicated.

Depending on the tribe, AIs may not participate for additional reasons. Researchers sometimes choose topics for their research study that reflect their personal or academic interest rather than a commonly recognized tribal priority. As a result AIs sometimes feel as though they are just a source of data. On the other hand, it is not always possible for the researcher to study the most pressing tribal priority, and a previously unrecognized issue may become of interest after discussion with an investigator. Prior to the start of this study, the genetics of PE would not have been among the top research priorities of the Turtle Mountain Band of Chippewa, but a number of steps were taken to inform the community about the relevance of this condition to the health of the tribe, to ensure that the research was conducted in a culturally appropriate way and to realize local benefit from the research. It is important that tribal nations benefit from the research and have information about the research returned back to the community [14]. It is also important that tribal nations have access to the data if not ownership of the data. AIs are also less likely to participate if biological samples were used in ways never intended. In order to avoid misunder- 
Table 2. Recommendations to consider when recruiting in American Indian communities

Potential participants are more likely to meet for a full consent interview if they can personally identify with the research.

Geneticists should ensure that communities distinguish between clinically oriented studies and the basic sciences related to populations.

The recruiter must ensure that participants are well informed during the consent process [15].

The recruiter must explain how the biological samples will be utilized throughout the study, where and how long they will be stored, what the researchers expect to find and what will become of the samples [15].

When recruiting potential participants in American Indian communities, traveling to potential participants' homes appears more effective and efficient.

Local community staff is extremely important for effective recruiting.

Recruiters should be as flexible and patient as possible.

Participants are more likely to prefer a gift certificate rather than a small gift.

The need to reschedule appointments is not unusual.

Advertising efforts have been questionable in their effectiveness.

Recruiters need to take extra time explaining why the potential participants are being contacted, what entities approved the study, how controls are selected, how contact information is obtained, and what will become of this information.

standings, it is important to have community input throughout the research process [14]. In an effort to keep the community involved and informed about the study, presentations were made to local medical staff, the elders group, the local health board, the Association of American Indian Physicians, and at local health fairs. Updates about the project were announced on local radio programs, posted in the newspapers and sent out to participants in the form of a newsletter. Engagement also occurred with the University of North Dakota Indians into Medicine organization, local high schools and summer enrichment programs.

Cultural beliefs might also exist that do not coincide with the research [14]. It is not surprising that there are vast cultural differences between indigenous and western peoples, but researchers may not be aware of the significant cultural differences between various indigenous groups [5]. Researchers should avoid grouping all tribes together and be knowledgeable of the issues specific to the tribe that is being studied [14]. Tribal experience with scientific research is quite variable, and this may have an important influence on their willingness to participate in genetic research [16]. The Turtle Mountain Band of Chippewa is more experienced with scientific research since a number of studies have been conducted in the community.

In addition, it may not be clear to AI research participants that medical research is often a slow, step-by-step process towards the development of a clinical intervention [5]. It is not unusual for research to take many years to complete and also for communities, desperate for a cure, to have a therapeutic misconception about research.

There are existing recommendations for conducting successful research with AIs [14], and there is plenty of information available that outlines respectful recruitment activities and practices that can be done to improve participation; however, our experience has led us to offer a number of additional recommendations to consider when recruiting in AI communities (table 2). Of particular interest is the need to travel to participants' homes. As a result, we not only experienced unanticipated travel expenses, but more time was spent on recruiting efforts than we had originally anticipated. The need to travel often posed as a barrier to recruiting those living on and off the reservation. However, traveling to potential participants' homes appears to be more effective and efficient. Also, it is important that researchers utilize local community staff for recruiting when possible. Most individuals on the reservation do not have a physical address, thus having a local recruiter is very helpful. Participants are also able to establish rapport with a local recruiter much easier than nonlocal recruiter. Participants generally preferred a USD 10 gift certificate in contrast to a locally made beaded lanyard, which we thought might be more acceptable from a cultural perspective. This could be due to the high rates of unemployment in this community and the versatility of a gift certificate. Although this experience was with an AI community, lessons learned could potentially apply to other rural or ethnic minority communities.

AI communities have been extensively studied, and we have explored many reasons why AIs might not wish to participate in a research study. In spite of this history though, AIs are willing to participate in research if investigators take the time to become aware of the history of research with AIs and take the steps that are necessary to be mindful and respectful of this history. 


\section{Acknowledgements}

This research and publication was made possible by NIH Grant Number P20 RR016741 from the INBRE Program of the National Center for Research Resources. The authors would like to acknowledge and give special thanks to the following: research participants, local elders group, Turtle Mountain Community
College, Quentin N. Burdick Health Care Facility, Tribal Chairmen's Health Board, Aberdeen Area Institutional Review Board, and the Turtle Mountain Band of Chippewa. They would also like to acknowledge the following students who worked for the study during this time: Melaine Antonio, Ronald Scott, Kristin Lujan, Tabitha Morin, and Rhonda Chase. They also appreciate Emil LaRocque's assistance in reviewing the manuscript.

\section{References}

$\checkmark 1$ Lee ET, Welty TK, Fabsitz R, Cowen LD, Le NA, Oopik AJ, Cucchiara AJ, Savage PJ, Howard BV: The Strong Heart Study. A study of cardiovascular disease in American Indians: design and methods. Am J Epidemiol 1990;132:1141-1155.

- 2 North KE, Howard BV, Welty TK, Best LG, Lee ET, Yeh JL, Fabsitz RR, Roman MJ, MacCluer JW: Genetic and environmental contributions to cardiovascular disease risk in American Indians: the strong heart family study. Am J Epidemiol 2003;157:303-314.

-3 Roberts JM, Pearson G, Cutler J, Lindheimer M; NHLBI Working Group on Research on Hypertension During Pregnancy: Summary of the NHLBI Working Group on Research on Hypertension During Pregnancy. Hypertension 2003;41:437-445.
4 DeMouy J: The Pima Indians: Pathfinders for Health. National Institute for Diabetes and Digestive and Kidney Diseases. 2002. Available at http://diabetes.niddk.nih.gov/ $\mathrm{dm} /$ pubs/pima/pathfind/pathfind.htm (accessed September 8, 2006).

5 Romero F: American Indian and Alaska Native Genetics Research Policy Formulation Meeting: Summary Meeting Report. Rio Rancho, NM, 2001.

6 Burhansstipanov L, Bemis L, Kaur J, Bemis G: Sample genetic policy language for research conducted with native communities. J Cancer Educ 2005;20(suppl 1):52-57.

7 Dalton R: Tribe blasts 'exploitation' of blood samples. Nature 2002;420:111.

8 Dalton R: When two tribes go to war. Nature 2004;430:500-502.

9 Turtle Mountain Community College: About us. Available at http://turtle-mountain.cc.nd.us/about/hist.asp.

10 U.S. Census Bureau. Available at http://factfinder.census.gov.

- 11 Best LG, Dorsam ST, Nadeau M, Burd L, Anderson CM: Genetic thrombophilia variants and risk for preeclampsia among American Indians. Hypertens Pregnancy 2009;28:8594.
12 Bodnar LM, Catov JM, Roberts JM: Racial/ ethnic differences in the monthly variation of preeclampsia incidence. Am J Obstet Gynecol 2007;196:324e1-324e5.

13 Dignan MB, Burhansstipanov LB, Hariton J, Harjo L, Rattler T, Lee R, Mason M: A comparison of two Native American Navigator formats: face-to-face and telephone. Cancer Control 2005;2(suppl 2):28-33.

14 Christopher S: Recommendations for conducting successful research with Native Americans. J Cancer Educ 2005;20(suppl 1):47-51.

15 Shelton BL: Consent and Consultation in Genetic Research on American Indians and Alaska Natives. Available at http://www. ipcb.org/publications/briefing_papers/files/ consent.html.

16 Bowekaty M, Davis DS: Cultural issues in genetic research with American Indian and Alaskan Native people. IRB 2003;25:12-15. 